\title{
Abandono na Educação Superior: um estudo do tipo Estado do Conhecimento
}

Leavers in higher education: a study of type State of Knowledge

Pricila Kohls dos Santos ${ }^{a}$

\section{Editor}

Maria Inês Côrte Vitoria PUCRS, RS, Brasil

\section{Equipe Editorial}

Pricila Kohls dos Santos PUCRS, RS, Brasil

Marcelo Oliveira da Silva PUCRS, RS, Brasil

Carla Spagnolo PUCRS, RS, Brasil Rosa Maria Rigo PUCRS, RS, Brasil

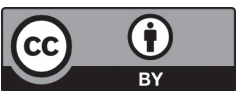

A matéria publicada neste periódico é licenciada sob forma de uma Licença Creative Commons - Atribuição 4.0 Internacional. http://creativecommons.org/licenses/by/4.0/
RESUMO: Este trabalho trata de uma pesquisa do tipo Estado do Conhecimento que versa sobre a temática do Abandono na Educação Superior presencial e a distância, tendo como objetivos identificar como a evasão está sendo apresentada em pesquisas acadêmicas, verificar os critérios de medição da evasão e evidenciar políticas de permanência nas pesquisas relacionadas à evasão na Educação Superior. O levantamento de dados se deu por meio de pesquisas no Portal de Teses da CAPES e nas Reuniões Anuais da ANPED, ambos no período entre 2000 a 2012. A análise realizada aponta para a necessidade de estudos voltados para a permanência dos estudantes na Educação Superior, bem como estudos que corroborem a necessidade de um olhar mais atento para a qualidade da oferta e do comprometimento institucional e também dos estudantes para com a Educação Superior.

Palavras-chave: Evasão. Permanência. Educação Superior. Educação presencial. Educação a Distância.

ABSTRACT: This paper deals with a study of type State of Knowledge which deals with the theme Abandonment of the Higher Education classroom and distance, with the objective to identify how evasion is being presented in academic research, check the criteria for measuring evasion and show policies spent on research related to dropout in higher education. The survey data was through research in Portal CAPES thesis and the Annual Meetings of ANPED, both during from 2000 to 2012. The analysis points to the need for studies on the permanence of Students in Higher Education, as well as studies to substantiate the need for a closer look for the quality of provision and the institutional commitment to the students and also with Higher Education.

Keyworks: Evasion. Permanence. Higher Education. Classroom education. Distance Education. 
educação das pessoas é fator essencial para o desenvolvimento e fortalecimento da sociedade e, por efeito, de um

país. Assim, as iniciativas de acesso, ampliação e qualificação da Educação devem ser priorizadas nos diferentes níveis de ensino. Sendo que a qualificação da Educação Básica pode implicar na qualificação da Educação Superior e vice-versa, ambas assumindo as consequências e responsabilidades das ações imbricadas em cada etapa/nível da Educação.

A Educação Superior, por sua vez, pode estar no cerne se for vista sob a ótica da formação dos sujeitos que atuarão na Educação Básica, uma vez que deve priorizar a qualificação do desenvolvimento de estudantes para atuarem em diferentes carreiras, incluindo a de professor, dentre os quais poderão auxiliar na constituição e desenvolvimento da sociedade.

No Brasil a Educação Superior é regulada pelo Ministério da Educação. Cabe aqui apresentar brevemente a finalidade da Educação Superior, empregada conforme as bases legais da Educação no Brasil na LDBEN 9.394 de 20.12.1996 a saber:

I - estimular a criação cultural e o desenvolvimento do espírito científico e do pensamento reflexivo;

II - formar diplomados nas diferentes áreas de conhecimento, aptos para a inserção em setores profissionais e para a participação no desenvolvimento da sociedade brasileira, e colaborar na sua formação contínua;

III - incentivar o trabalho de pesquisa e investigação científica, visando o desenvolvimento da ciência e da tecnologia e da criação e difusão da cultura, e, desse modo, desenvolver o entendimento do homem e do meio em que vive;

IV - promover a divulgação de conhecimentos culturais, científicos e técnicos que constituem patrimônio da humanidade e comunicar o saber através do ensino, de publicações ou de outras formas de comunicação;

$\mathrm{V}$ - suscitar o desejo permanente de aperfeiçoamento cultural e profissional e possibilitar a correspondente concretização, integrando os conhecimentos que vão sendo adquiridos numa estrutura intelectual sistematizadora do conhecimento de cada geração;

VI - estimular o conhecimento dos problemas do mundo presente, em particular os nacionais e regionais, prestar serviços especializados à comunidade e estabelecer com esta uma relação de reciprocidade;

VII - promover a extensão, aberta à participação da população, visando à difusão das conquistas e benefícios resultantes da criação cultural e da pesquisa científica e tecnológica geradas na instituição.

Para encontrar espaço para execução da finalidade da Educação Superior, houve uma ampliação do acesso e da oferta do número de vagas. Porém, tal fenômeno ocorreu em maior número pela iniciativa privada. Ainda que ações governamentais tenham sido executadas para ampliação da oferta em instituições públicas de Educação Superior. 
A ampliação do acesso nos remete ao fato de que a expansão da Educação Superior não teve apenas um sentido de ampliação geográfica, mas também um sentido de ampliação de oportunidades de acesso para setores da classe média até então excluídos desse nível de ensino. Esta ampliação do acesso confunde-se em grande parte com o próprio processo de privatização, pois ocorreu principalmente como resultado da forte excludência historicamente reinante nas universidades públicas. (RISTOFF, 2008, p. 43)

De acordo com o Censo da Educação Superior de 2011, 88,0\% das Instituições de Ensino Superior (IES) são privadas, sendo que apenas $12,0 \%$ das instituições são públicas. Além desse número, outro fator a se considerar é a distribuição geográfica das instituições, como apresentado na figura1, quase metade das IES localizam-se na região sudeste do Brasil, o que corresponde a cerca de $48 \%$ do total, ou seja, 1.150 instituições.

Figura 1 - Número de Instituições de Educação Superior, segundo as Regiões
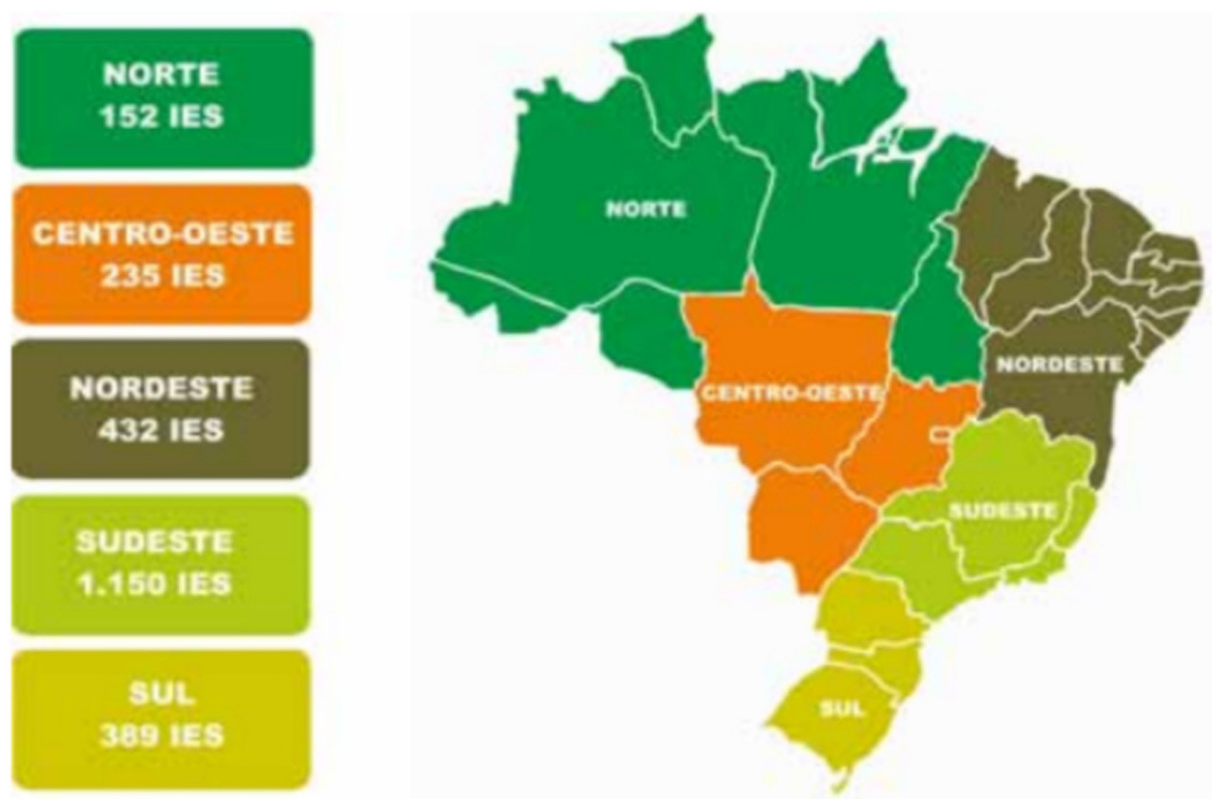

Fonte: MEC/INEP (2013). 
Tais aspectos, sejam estes a localização e a predominância de IES privadas, mesmo com programas de incentivo do governo, como FIES ${ }^{1}$ e PROUNI ${ }^{2}$, corroboram para ainda haver uma "excludência" relacionada ao acesso na Educação Superior brasileira.

Em relação a vagas e ingressos, o Censo de 2011 contabilizou 6.739 .689 de matrículas em cursos de graduação, sendo 26,3\% (1.773.315) das matrículas efetuadas em IES públicas e 73,7\% (4.966.374) em IES privadas. O Plano Nacional de Educação 2011 - 2020, dentre as metas estabelecidas, prevê elevar, mantendo a qualidade, a taxa bruta ${ }^{3}$ de matrícula na Educação Superior para $50 \%$ e a taxa líquida ${ }^{4}$ para $33 \%$ da população de 18 a 24 anos, atualmente a taxa líquida é de 14,6\% (INEP, 2011).

A Tabela 1 apresenta a comparação dos dados de matrículas em relação ao número de ingressos e concluintes de graduação segundo a modalidade de ensino e regiões geográficas.

Tabela 1 - Número Ingressos por Processo Seletivo, Matrículas e Concluintes em Cursos de Graduação Presencial por Sexo, segundo a Categoria Administrativa - Brasil - 2012

\begin{tabular}{lccc}
\hline $\begin{array}{c}\text { Categoria } \\
\text { Administrativa }\end{array}$ & $\begin{array}{c}\text { Ingressos por } \\
\text { processo seletivo }\end{array}$ & Matrículas & Concluintes \\
\cline { 2 - 4 } & Total & Total & Total \\
\hline Total & $\mathbf{1 . 9 7 0 . 3 9 3}$ & $\mathbf{5 . 9 2 3 . 8 3 8}$ & $\mathbf{8 7 6 . 0 9 1}$ \\
\hline Pública & 462.097 & $1.715,752$ & 202.394 \\
Federal & 277.501 & 985.202 & 96.270 \\
Estadual & 140.175 & 560.505 & 78.489 \\
Municipal & 44.421 & 170.045 & 27.635 \\
Privada & 1.508 .295 & 4.208 .086 & 673.697 \\
\hline
\end{tabular}

Fonte: MEC/INEP (2013).

1 O Fundo de Financiamento Estudantil (Fies) é um programa do Ministério da Educação destinado a financiar a graduação na Educação Superior de estudantes matriculados em instituições não gratuitas. (BRASIL, 2005)

2 Programa Universidade para Todos (Prouni) é um programa do Ministério da Educação, que concede bolsas de estudos em instituições privadas de ensino superior. (BRASIL, 2005)

3 A taxa de escolarização bruta expressa o percentual da população de 18 a 24 anos que declara frequentar escola.

4 A taxa de escolarização líquida, por sua vez, identifica o percentual da população de 18 a 24 anos que declara cursar graduação. 
Para os percentuais e números apresentados em relação a matrículas, é possível verificar que o número percentual de concluintes corresponde a $15 \%$ das matrículas, $34,8 \%$ corresponde a matrículas de ingressantes e $49,8 \%$ das matrículas correspondem aos estudantes que se mantém matriculados em cursos de graduação de um ano para outro. Porém, não é possível mensurar o percentual desses estudantes que abandonam os estudos antes de concluí-los, ou seja, não é possível afirmar claramente qual o índice de evasão na Educação Superior no Brasil.

A evasão corresponde ao aluno que ingressou na Educação Superior, mas, em algum momento do curso, não efetivou sua matrícula. Todavia, mesmo desligando-se do ensino, entende-se que isso requer uma postura ativa, pois pressupõe que o mesmo decide desligar-se por sua própria responsabilidade. Outra concepção pode ser analisada sob a ótica de Dilvo Ristoff quando afirma que

Parcela significativa do que chamamos evasão, no entanto, não é exclusão mas mobilidade, não é fuga, não é desperdício mas investimento, não é fracasso - nem do aluno nem do professor, nem do curso ou da Instituição - mas tentativa de buscar o sucesso ou a felicidade, aproveitando as revelações que o processo natural de crescimento do indivíduo faz sobre suas reais potencialidades. (RISTOFF, 1999, p. 125)

Nesta direção, aponta-se como necessárias pesquisas que evidenciem as causas da evasão na Educação Superior, bem como estudos que apontem as condições de permanência dos estudantes neste nível de ensino. A partir desta configuração, este artigo apresenta uma breve análise realizada no Banco de Teses da CAPES e nas Reuniões Anuais da ANPED nos anos de 2000 a 2012 sobre Evasão na Educação Superior a Distância.

Ao realizar esta análise, objetiva-se saber como a Evasão na Educação Superior, presencial e a distância, está sendo pesquisada, qual enfoque está sendo dado, qual o universo pesquisado, em qual ótica a evasão está sendo apresentada em pesquisas acadêmicas, quais os critérios de medição da evasão, bem como evidenciar políticas de permanência nas pesquisas relacionadas à evasão na Educação Superior.

\section{Metodologia}

A metodologia adotada neste estudo é de caráter qualitativo exploratório, pautado na pesquisa bibliográfica. Para a análise dos dados utilizou-se a Análise de Conteúdo para ser possível elaborar novos achados e conhecimento acerca do fenômeno ora investigado, a saber: Evasão na Educação Superior.

O corpus dessa pesquisa foi composto por 3 teses e 6 dissertações, disponíveis no Banco de Teses da CAPES, além de 2 artigos publicados nas Reuniões Anuais da ANPED, ambos a partir dos descritores: evasão, Educação 
Superior, ensino superior, permanência. O recorte temporal dado à esta pesquisa foi o período de 2000 a 2012 , uma vez que este período representa a maior incidência de trabalhos sobre a temática ora proposta.

A partir da seleção dos trabalhos, os mesmos foram analisados e reunidos em quatro categorias: Olhar em relação à Gestão, Olhar em relação ao Estudante, Políticas Públicas e Políticas de Permanência, das quais os resultados das análises são apresentados na próxima seção. Para tal, foi utilizada a Análise de Conteúdo que, segundo Bardin,

É um conjunto de técnicas de análise das comunicações. Não se trata de um instrumento, mas de um leque de apetrechos; ou, com maior rigor, será um único instrumento, mas marcado por uma grande disparidade de formas e adaptável a um campo de aplicação muito vasto: as comunicações. (BARDIN, 2010, p. 33)

Assim foi realizada a leitura flutuante do material para, de acordo com os objetivos e questões de estudo, fosse definida a unidade de registro e as categorias de análise. Na fase de exploração do material foi realizado o processo de codificação pelo recorte dos textos em temas, os quais foram identificados para se chegar a uma correspondência entre a sua presença/ausência e os significados inferidos, os quais são apresentados os resultados na seção seguinte.

\section{Resultados}

Ao analisarmos os trabalhos, observamos que dos 11 trabalhos publicados entre os anos de 2000 a 2012 referentes à temática Evasão na Educação SuperiorPresencial e a Distância, 8 trabalhos correspondiam à área da Educação, 2 da Administração e 1 do Planejamento Urbano e Desenvolvimento Regional. Quanto à metodologia utilizada, 6 tiveram abordagem qualitativa/quantitativa, 3 quantitativa e 2 qualitativa. Em relação à categoria administrativa dos locais pesquisados, dos 11 trabalhos 6 foram realizados em instituições públicas e 5 em instituições privadas.

Em relação ao recorte temporal utilizado no presente estudo, percebe-se um considerável silenciar, em relação à temática aqui apresentada, nos anos de 2000 a 2003 e 2005 a 2008, sendo que o maior número de publicações foi realizada no ano de 2012. Conforme pode ser observado no Gráfico 1.

Ainda em relação à caracterização do corpus da pesquisa, outra informação relevante a considerar é a modalidade de ensino na qual foram realizados estudos. Destes, 3 estudos foram realizados na modalidade presencial, 3 na modalidade a distância e apenas um estudo foi realizado nas modalidades presencial e a distância (Gráfico 2). 
Gráfico 1 - Corpus da pesquisa

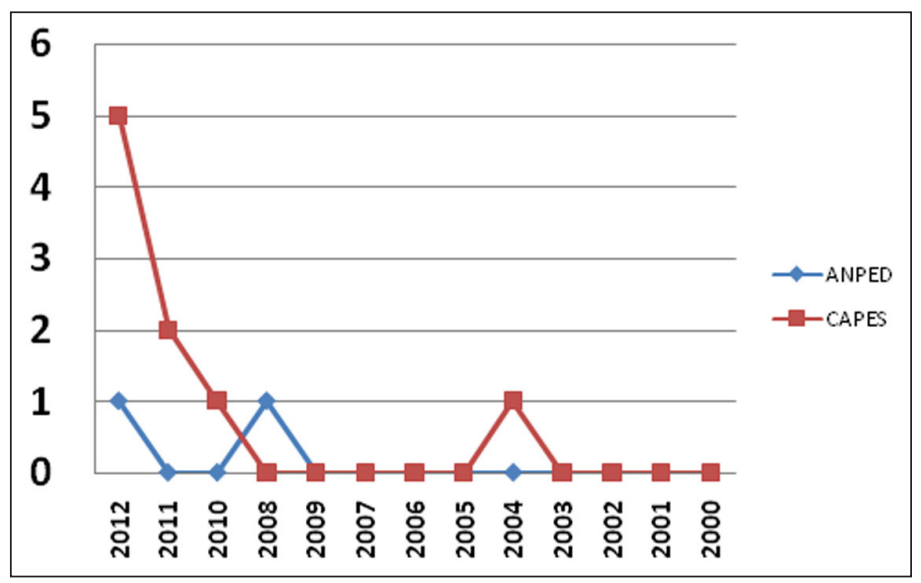

Fonte: Elaborado pela autora.
Gráfico 2 - Caracterização das IES quanto a modalidade de ensino

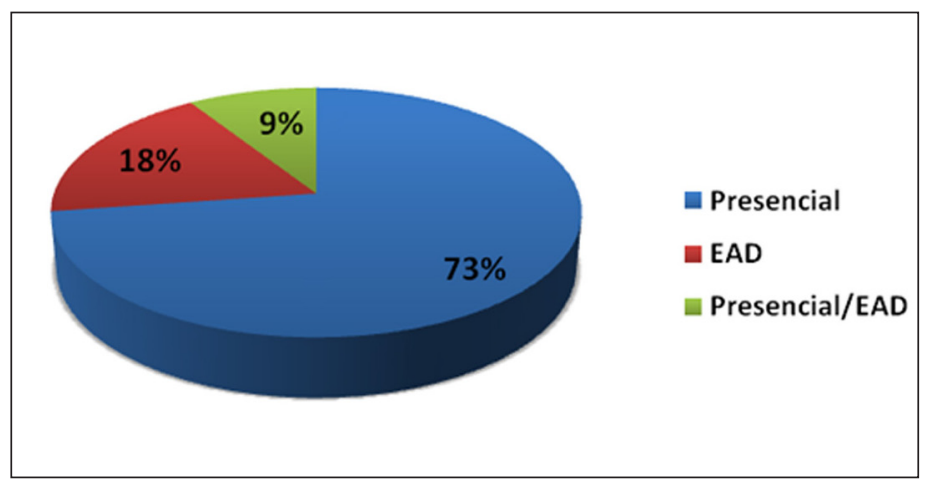

Fonte: Elaborado pela autora.

Diante das informações gerais apresentadas, as quais surgiram a partir da leitura e análise das publicações selecionadas, emergiram as seguintes categorias: Olhar em relação à Gestão (4 trabalhos), Olhar em relação ao Estudante (10 trabalhos), Políticas Públicas (2 trabalhos) e Políticas de Permanência (3 trabalhos), podendo haver trabalhos presentes em mais de uma categoria de análise.

\section{Olhar em relação à gestão}

Nesta categoria, Amidani (2004) constata a necessidade de um olhar voltado para as condições estruturais e administrativas institucionais que caracterizaram o funcionamento da graduação a distância, pois este foi um fator levantado pelos estudantes como contribuinte para o abandono do curso e ainda ressalta que este fenômeno sofreu influências de aspectos intrínsecos ao curso. E ainda salienta a importância da integração acadêmica, viabilizada pela gestão institucional como ponto para auxiliar a permanência do aluno na EAD. 
Já Borges (2011) focou sua atenção nos fatores que levaram à evasão dos estudantes nos cursos de Administração, na qual destacou "a necessidade de uma intervenção por parte dos dirigentes no sentido de reter os alunos promovendo ações que viabilizem a permanência dos mesmos até a conclusão do curso".

Lopes, Lisniowski e Jesus (2012) afirmam que é papel da gestão considerar o perfil dos alunos e focar nos fatores que apresentam maior potencial para a implementação de estratégias de mudanças. A pesquisa também focou nos aspectos que levam os alunos a desistirem dos estudos, porém este se encaixa na categoria relacionada aos estudantes.

O estudo de Silva (2012) propõe comparar os resultados da evasão nas modalidades presencial e a distância, sendo que aponta para uma forte necessidade da gestão acadêmica e institucional refletir sobre a possibilidade de integração de três visões filosóficas: "Cognitivismo, Construtivismo e Conectivismo que se interrelacionam na gestão acadêmica de cursos superiores pela unicidade da educação vislumbrada pelo blended learning como tendência futura para a Educação Superior".

Ao considerar a gestão como categoria de análise acredita-se na importância do trabalho e da equipe de gestão também com foco no estudante e na qualificação da oferta de Educação, tal como evidenciado nas publicações analisadas. Ou seja, o papel da gestão está intrinsicamente ligada à aspectos relacionados com a evasão e, por conseguinte, uma boa gestão pode vir a contribuir para a permanência estudantil.

\section{Olhar em relação ao estudante}

Esta categoria possui 10 trabalhos analisados, sendo que seus resultados partem do ponto de vista que o foco da evasão está mais relacionado ao estudante e às suas posturas e limitações em relação estudos.

No estudo de Amidani (2004), por se tratar de Educação a Distância, foi realizada pesquisa com alunos, tutores, direção de polo e funcionários, através de questionário realizado via telefone ou internet e também presencialmente para os tutores e gestores, levando em consideração as experiências adquiridas ao longo do curso de graduação realizado. Como resultado, foram apontados como fatores principais para evasão nos cursos a distância as dificuldades inerentes apenas ao aluno. O autor afirma que a evasão foi "decorrente das dificuldades dos alunos em conciliar estudo e trabalho, obrigações referentes à profissão, atenção à família, além da formação escolar anterior precária, havendo destaque deste último" (p. 46).

Já Pinto (2010) aponta aspectos positivos em relação ao estudante ao afirmar que "a presença dos alunos bolsistas do Prouni não impacta negativamente a qualidade da Educação Superior", sendo que tal programa estimula a permanência dos estudantes na universidade, uma vez que o mesmo é incentivado pelo mérito obtido no ENEM (Exame Nacional do Ensino Médio), que proporcionou o ingresso na Educação Superior. Sendo que há indícios 
de rendimento positivo dos estudantes, justificado pela maior motivação e interesse destes alunos valorizando a oportunidade garantida pelo PROUNI para o acesso à Universidade. Porém, salienta que os dados também evidenciam uma significativa evasão, que aponta o rendimento acadêmico insuficiente como um dos principais motivos de tal fenômeno.

Borges (2011), tendo realizado sua pesquisa com estudantes e coordenadores de curso, apresenta como dado para evasão a questão relacionada a questões financeiras, a dificuldade em acompanhar o curso e fatores relacionados à qualidade do curso ou ainda a adaptação do aluno à instituição como causas para a desistência. Já Rocha (2012) analisou a evasão no âmbito dos estudantes oriundos do PROUNI. Para tal, fez uso de questionários e entrevistas, junto a estudantes bolsistas e gestores, em uma IES privada, as quais apontaram que o número de evadidos ou reprovados é relativamente baixo se comparado com os demais estudantes da instituição. Destaca também que as dificuldades dos bolsistas estão centradas no processo de aprendizagem ou no âmbito financeiro e que estas dificuldades não desaparecem apenas com o ingresso na graduação.

Silva (2012) propõe-se a realizar uma análise comparativa entre o curso de administração presencial e distância, identificando as variáveis que influenciam o processo de permanência dos alunos de Administração sendo que apresenta com maior ênfase questões relacionadas a dificuldades dos estudantes em relação a: atributos individuais, trabalho e estágio, contexto familiar, escolaridade anterior, uso das TICs, interação docente e discente, compromisso pessoal com os estudos e com a instituição. Detregiachi Filho (2012) também apresenta questões relacionadas à postura do estudante, seu comprometimento com os estudos como fator relevante para a evasão e afirma que "apesar da maioria das dificuldades apontadas pelos alunos serem de ordem acadêmica, elas competem de perto com aquelas de ordem financeira e econômicas".

Pereira Júnior (2012) propõe um estudo fundamentado em Vincent Tinto, o qual aponta que estudantes não integrados aos sistemas acadêmico e social do ambiente universitário podem ter seus níveis de compromisso com o graduar-se afetados. A partir de sua pesquisa, afirma que a questão do comprometimento está intimamente ligada à possível desistência do curso e que o fator empregabilidade tem uma relação significante com o fenômeno da evasão, pois este é o que mais motiva o estudante a comprometer-se com seus estudos e com a instituição a qual está vinculado.

Piacentini (2012) buscou analisar a temática da evasão computando o número de estudantes evadidos e triangulando os dados de questionários realizados com estudantes ativos, evadidos e docentes do curso de Zootecnia. Obteve como resultados para as possíveis causas da evasão: a escolha precoce da profissão que está ligada à maturidade e indecisão; o nível socioeconômico dos discentes, que afeta diretamente na permanência na Instituição; 
e suas habilidades acadêmicas, que estão relacionadas com sua trajetória escolar e ao pouco envolvimento com o curso.

Já Velloso e Cardoso (2011) propuseram-se a analisar e comparar índices de abandono entre estudantes cotistas e não-cotistas. Tal análise evidencia uma pequena diferença entre alunos cotistas e não-cotistas em relação à evasão e apontam que a evasão se dá pelo motivo de o estudante não cumprir condições para continuar na instituição - como seguir um número mínimo de disciplinas por semestre, o que neste estudo apresenta uma maior desistência por parte de alunos não-cotistas, ao contrário das expectativas iniciais preconizadas pelo autor.

Lopes, Lisniowski, Jesus (2012) realizaram um estudo acerca da evasão em um curso de Pedagogia a distância. Para tal, realizou pesquisa com os alunos evadidos através de questionário contendo 18 questões, realizado via telefone. As questões oportunizaram levantar o perfil dos alunos, bem como as principais causas da evasão, dentre as quais foram destacadas: a ausência da interação presencial com os colegas, professores e tutores; a excessiva carga de leitura e trabalhos a realizar; a falta de motivação para continuar estudando e a falta de hábitos e técnicas de estudo individualizados; a dificuldade de organizar o tempo disponível para os estudos e a dificuldade de conciliar estudo e trabalho.

Observa-se, a partir das análises realizadas, uma preocupação dos autores em levantar os aspectos que acarretam a evasão dos estudantes, porém percebe-se certa inferência a priori evidenciando as limitações dos estudantes e talvez uma falta de espaço para levantamentos relacionados à corresponsabilidade dos docentes e das instituições em relação às dadas limitações/dificuldades dos estudantes. Diante do exposto, parece urgir a necessidade de estudos que aprofundem o aspecto institucional relacionado à evasão em comparação com os aspectos relacionados ao estudante.

\section{Políticas públicas}

No que tange a Políticas Públicas, o estudo realizado por Pinto (2010) apresenta um aspecto positivo relacionado às condições dos estudantes oriundos do PROUNI, ao ressaltar que o fato de o estudante bolsista ter bom rendimento e estímulo a continuar seus estudos é um dado que deve estimular o repensar das políticas públicas quanto à ampliação dos programas de estímulo ao ingresso no ensino superior, prevendo maior apoio aos bolsistas durante o percurso de formação. Reforça a importância das políticas de ação afirmativa, com o intuito de minorar as diferenças de oportunidades educacionais que se evidenciam em sociedades desiguais, como é o caso do Brasil.

Rocha (2012) apresenta um diálogo entre os aspectos relacionados ao direito à educação e as políticas públicas de acesso, tendo como foco principal o PROUNI. Para tanto, realizou entrevistas com estudantes e 
gestores com o intuito de mensurar os índices de evasão/permanência e repetência em uma instituição privada. Observa que, para a democratização do Ensino Superior, são fundamentais as políticas para a ampliação do acesso.

\section{Políticas de permanência}

Esta categoria de análise é composta por 3 trabalhos que apontam perspectivas em relação a ações voltadas para permanência e/ou qualificação da educação como uma das vias para permanência dos estudantes na Educação Superior.

Lourenço (2011), em sua dissertação de mestrado, apresenta o Marketing de permanência como um viés a ser adotado pelas instituições de ensino ao longo da trajetória do estudante na IES, além disso ressalta que grande parte das instituições prioriza as ações de marketing para a conquista de novos alunos, mas não investem na sua permanência em igual proporção. A partir do estudo realizado nos cursos de graduação em Administração, Ciências Contábeis e Ciência da Computação de uma IES privada, o autor aponta que "as IES trabalham o marketing de relacionamento até o aluno ingressar no curso (pré-venda), mas parecem falhar durante o processo de prestação de serviço e na pós-venda, fatos que influenciam na deserção acadêmica. A permanência do aluno na instituição de ensino passa, diante do enfoque desta pesquisa, a ser uma consequência de estratégias bem sucedidas de marketing de relacionamento, desde o ingresso do aluno na instituição de ensino".

O trabalho de Rocha (2011), o qual analisou os índices de evasão, repetência e permanência dos estudantes oriundos do PROUNI em uma instituição privada, afirma que, além de priorizar o acesso é preciso, também, vislumbrar políticas voltadas para a permanência dos estudantes, uma vez que se constatou que as dificuldades dos estudantes bolsistas, seja no processo de aprendizagem ou financeiramente, não desaparecem apenas com o ingresso na graduação. E ainda afirma que este olhar para a permanência é necessário para que se garanta a efetiva democratização e a inclusão na Educação Superior.

Já Piacentini (2012) ao analisar o curso de Zootecnia, apresenta como necessário e fundamental um olhar para a qualidade da permanência do estudante no curso e afirma que, a partir da identificação das perspectivas, foram sugeridos alguns programas, tais como: Programa de Tutoria; Bolsas de auxílio aos discentes carentes e; Programa de Nivelamento, que podem auxiliar na minimização da problemática evasão no curso, promovendo, assim, a permanência do aluno na Instituição.

Para elucidar o panorama das publicações apresentadas anteriormente, a Tabela 2 consta das informações acerca de cada trabalho analisado. 
Tabela 2 - Descrição das teses e dissertações

\begin{tabular}{|c|c|c|c|c|c|}
\hline \multicolumn{6}{|c|}{ TABELA ESTADO DE CONHECIMENTO } \\
\hline \multicolumn{6}{|c|}{ 35a Reunião Anual da ANPED - 2012} \\
\hline N. Trabalho & \multicolumn{2}{|c|}{ Autor(es) } & Palavras-chave & Titulo & Metodologia \\
\hline $\begin{array}{l}\text { GT11 - } 2385 \\
\text { Pública }\end{array}$ & \multicolumn{2}{|c|}{$\begin{array}{l}\text { Ruth Gonçalves } \\
\text { de Faria Lopes }\end{array}$} & & $\begin{array}{l}\text { POLÍTICAS PÚBLICAS DE EDUCAÇÃO SUPERIOR A } \\
\text { DISTÂNCIA: UM ESTUDO PRELIMINAR DAS CAUSAS }\end{array}$ & \multirow[t]{3}{*}{$\begin{array}{l}\text { Quantitativa/ } \\
\text { Qualitativa }\end{array}$} \\
\hline & \multirow{2}{*}{\multicolumn{2}{|c|}{$\begin{array}{l}\text { Simone Aparecida Lisniowski } \\
\text { Girlene Ribeiro de Jesus }\end{array}$}} & & \multirow{2}{*}{$\begin{array}{c}\text { OFERECIDO NO ÂMBITO DO SISTEMA UNIVERSIDADE } \\
\text { ABERTA DO BRASIL }\end{array}$} & \\
\hline & & & & & \\
\hline \multicolumn{6}{|c|}{ 31a- Reunião Anual da ANPED - 2008} \\
\hline N. Trabalho & \multicolumn{2}{|c|}{ Autor(es) } & Palavras-chave & Titulo & Metodologia \\
\hline \multirow{2}{*}{$\begin{array}{l}\text { GT11 - } 4981 \\
\text { Pública }\end{array}$} & \multirow{2}{*}{\multicolumn{2}{|c|}{$\begin{array}{l}\text { Jacques Velloso } \\
\text { udete Batista Cardoso }\end{array}$}} & & \multirow{2}{*}{$\begin{array}{l}\text { EVASÃO NA EDUCAÇÃO SUPERIOR: ALUNOS COTISTAS E } \\
\text { NÃOCOTISTAS NA UNIVERSIDADE DE BRASÍLIA }\end{array}$} & \multirow[t]{2}{*}{ Quantitativa } \\
\hline & & & & & \\
\hline \multicolumn{6}{|c|}{$\begin{array}{c}\text { Banco de Teses CAPES }-2012 \\
5 \text { trabalhos }-3 \text { mestrado e } 2 \text { doutorado }\end{array}$} \\
\hline Área & Nível & Autor(es) & Palavras-chave & Titulo & Metodologia \\
\hline $\begin{array}{l}\text { Educação } \\
\text { Pública }\end{array}$ & Mestrado & $\begin{array}{l}\text { Claudia Cristina } \\
\text { Piacentini }\end{array}$ & $\begin{array}{l}\text { Evasão, Zootecnia, } \\
\text { Universidade, } \\
\text { Programas, } \\
\text { Permanência }\end{array}$ & $\begin{array}{l}\text { REPROVAÇÃO, ABANDONO E EVASÃO: UM ESTUDO DE } \\
\text { CASO NO CURSO DE BACHARELADO EM ZOOTECNIA DA } \\
\text { UNIVERSIDADE TECNOLÓGICA FEDERAL DO PARANÁ }\end{array}$ & $\begin{array}{l}\text { Qualitativa/ } \\
\text { Quantitativa }\end{array}$ \\
\hline Área & Nível & Autor(es) & Palavras-chave & Titulo & Metodologia \\
\hline $\begin{array}{l}\text { Educação } \\
\text { Pública }\end{array}$ & Mestrado & Edgar Pereira Júnior & $\begin{array}{l}\text { Evasão. Educação } \\
\text { Superior. Graduação. }\end{array}$ & $\begin{array}{c}\text { COMPROMISSO COM O GRADUAR-SE, COM A INSTITUIÇÃO } \\
\text { E COM O CURSO: ESTRUTURA FATORIAL E RELAÇÂO } \\
\text { COM A EVASÃO }\end{array}$ & Quantitativa \\
\hline Área & Nível & Autor(es) & Palavras-chave & Titulo & Metodologia \\
\hline $\begin{array}{l}\text { Educação } \\
\text { Pública }\end{array}$ & Doutorado & $\begin{array}{l}\text { Edson Detregiachi } \\
\text { Filho }\end{array}$ & $\begin{array}{l}\text { Educação tecnológica. } \\
\text { Evasão educacional. } \\
\text { Educação profissional. }\end{array}$ & $\begin{array}{c}\text { A EVASÃO ESCOLAR NA EDUCAÇÃO TECNOLÓGICA: } \\
\text { ESTUDO DE UMA UNIDADE DO CENTRO ESTADUAL DE } \\
\text { EDUCAÇÃO TECNOLÓGICA PAULA SOUZA }\end{array}$ & Quantitativa \\
\hline Área & Nível & Autor(es) & Palavras-chave & Titulo & Metodologia \\
\hline $\begin{array}{l}\text { Administração } \\
\text { Privada }\end{array}$ & Doutorado & $\begin{array}{l}\text { João Augusto Ramos } \\
\text { e Silva }\end{array}$ & $\begin{array}{l}\text { Ensino a distância, } \\
\text { Evasão escolar, } \\
\text { Administração. }\end{array}$ & $\begin{array}{c}\text { A PERMANENCIA DE ALUNOS NOS CURSOS PRESENCIAIS } \\
\text { E A DISTÂNCIA DE ADMINISTRAÇÂO: CONTRIBUIÇÕES } \\
\text { PARA GESTÂO ACADÊMICA }\end{array}$ & Qualitativa \\
\hline Área & Nível & Autor(es) & Palavras-chave & Titulo & Metodologia \\
\hline $\begin{array}{l}\text { Educação } \\
\text { Privada }\end{array}$ & Mestrado & $\begin{array}{l}\text { Terezinha Cristina } \\
\text { da Costa Rocha }\end{array}$ & $\begin{array}{l}\text { Ensino Superior; } \\
\text { Políticas Públicas } \\
\text { Educacionais. }\end{array}$ & $\begin{array}{c}\text { POLITIICAS PÚBLICAS PARA O ENSINO SUPERIOR: } \\
\text { ESTUDO SOBRE A INCLUSÃO E O DESEMPENHO } \\
\text { ACADÊMICO DOS BOLSISTAS DO PROUNI EM UMA } \\
\text { IES PRIVADA DE MINAS GERAIS }\end{array}$ & $\begin{array}{l}\text { Qualitativa/ } \\
\text { Quantitativa }\end{array}$ \\
\hline
\end{tabular}


Tabela 2 (conclusão)

\begin{tabular}{|c|c|c|c|c|c|}
\hline \multicolumn{6}{|c|}{ TABELA ESTADO DE CONHECIMENTO } \\
\hline \multicolumn{6}{|c|}{$\begin{array}{l}\text { Banco de Teses CAPES - } 2011 \\
2 \text { trabalhos Mestrado profissional }\end{array}$} \\
\hline Área & Nível & Autor(es) & Palavras-chave & Titulo & Metodologia \\
\hline $\begin{array}{l}\text { Administração } \\
\text { Privada }\end{array}$ & $\begin{array}{l}\text { Mestrado } \\
\text { profissional }\end{array}$ & $\begin{array}{l}\text { Grasiele Aparecida } \\
\text { Lourenço }\end{array}$ & $\begin{array}{l}\text { Mkt de serviço. } \\
\text { Mkt de relacionamento. } \\
\text { Retenção de clientes. }\end{array}$ & $\begin{array}{c}\text { ESTRATÉGIAS DE RELACIONAMENTO PARA RETENÇÃO DE } \\
\text { CLIENTES: UM ESTUDO DE CASO EM UMA INSTITUIÇÃO DE } \\
\text { ENSINO SUPERIOR PRIVADA NA REGIÃO METROPOLITANA } \\
\text { DE CAMPINAS }\end{array}$ & $\begin{array}{l}\text { Qualitativa/ } \\
\text { Quantitativa }\end{array}$ \\
\hline Área & Nível & Autor(es) & Palavras-chave & Titulo & Metodologia \\
\hline $\begin{array}{l}\text { Planejamento } \\
\text { Urbano e Regional } \\
\text { Privada }\end{array}$ & $\begin{array}{l}\text { Mestrado } \\
\text { profissional }\end{array}$ & $\begin{array}{l}\text { Sandra Marques } \\
\text { Borges }\end{array}$ & $\begin{array}{l}\text { Evasão. } \\
\text { Ensino Superior. } \\
\text { Educação. }\end{array}$ & $\begin{array}{c}\text { FATORES DETERMINANTES DA EVASÃO ESCOLAR } \\
\text { NO ENSINO SUPERIOR: O ESTUDO DE CASO DO } \\
\text { ILES/ULBRA DE ITUMBIARA }\end{array}$ & $\begin{array}{l}\text { Qualitativa/ } \\
\text { Quantitativa }\end{array}$ \\
\hline \multicolumn{6}{|c|}{$\begin{array}{c}\text { Banco de Teses CAPES - } 2010 \\
1 \text { trabalho doutorado }\end{array}$} \\
\hline Área & Nível & Autor(es) & Palavras-chave & Titulo & Metodologia \\
\hline $\begin{array}{l}\text { Educação } \\
\text { Privada }\end{array}$ & Doutorado & $\begin{array}{l}\text { Marialva Linda } \\
\text { Moog Pinto }\end{array}$ & $\begin{array}{l}\text { Educação Superior, } \\
\text { Indicadores de } \\
\text { qualidade, PROUNI. }\end{array}$ & $\begin{array}{l}\text { QUALIDADE DA EDUCAÇÃO SUPERIOR E O PROUNI: } \\
\text { LIMITES E POSSIBILIDADES DE UMA POLÍTICA DE } \\
\text { INCLUSÃO }\end{array}$ & Qualitativa \\
\hline \multicolumn{6}{|c|}{$\begin{array}{c}\text { Banco de Teses CAPES - } 2004 \\
1 \text { trabalho mestrado }\end{array}$} \\
\hline Área & Nível & Autor(es) & Palavras-chave & Titulo & Metodologia \\
\hline $\begin{array}{l}\text { Educação } \\
\text { Pública }\end{array}$ & Mestrado & Cassandra Amidani & $\begin{array}{l}\text { Educação a Distância. } \\
\text { Ensino Superior. } \\
\text { Evasão. }\end{array}$ & $\begin{array}{l}\text { EVASÃO NO ENSINO SUPERIOR A DISTÂNCIA: O CURSO } \\
\text { DE LICENCIATURA EM MATEMÁTICA A DISTÂNCIA DA } \\
\text { UNIVERSIDADE FEDERAL FLUMINENSE/CEDERJ? }\end{array}$ & $\begin{array}{l}\text { Qualitativa/ } \\
\text { Quantitativa }\end{array}$ \\
\hline
\end{tabular}

Fonte: Elaborado pela autora.

\section{Considerações finais}

Nesta análise observamos que há um singelo movimento de expansão de olhares em relação à Evasão na Educação Superior, uma vez que há um crescimento nas publicações no ano de 2012 versando sobre o tema em questão. É possível, também, observar que grande parte das publicações é idealizada com o intuito de verificar os motivos da evasão, não apresentando ênfase para os motivos da permanência de estudantes na Educação Superior. 
Corroborando com tal observação, percebemos um olhar acentuado para as deficiências e dificuldades dos estudantes em permanecer na universidade, sendo que os motivos mais apontados são: falta de motivação para continuar estudando e a falta de hábitos e técnicas de estudo individualizadas, a dificuldade de organizar o tempo disponível para os estudos, a dificuldade de conciliar estudo e trabalho, formação escolar anterior precária. Tais olhares denotam a carência de estudos que verifiquem as condições da oferta de educação, bem como a qualidade do ensino dirigido aos estudantes.

Embora apareçam aspectos em relação à gestão acadêmica, estes surgem em proporção significativamente menor do que os olhares em relação ao comprometimento do estudante. Acredita-se ser necessário realizar estudos que triangulem a qualidade do ensino, o comprometimento institucional e o comprometimento do estudante em relação à Educação Superior.

Observamos também a importância de estudos consistentes que primem pelo viés da permanência ao analisar a evasão e/ou abandono na Educação Superior, para que, assim, possam ser levantadas possibilidades de mudança e de qualificação do acesso, permanência e conclusão dos estudos em instituições de Educação Superior. Desta forma, oportuniza-se a todos os envolvidos com educação, incluindo os estudantes, um envolvimento máximo e qualificado nas relações entre os pares e na construção de uma formação constante e continuada com vistas à construção de uma sociedade mais justa, fraterna e consciente de que a cada ação podemos mudar e transformar o mundo ao nosso redor.

\section{Referências}

AMIDANI, Cassandra. Evasão no Ensino Superior a Distância: o curso de Licenciatura em Matemática a Distância da Universidade Federal Fluminense/CEDERJ. 200f. Dissertação (Mestrado em Educação) - Universidade de Brasília. Brasília. 2004.

BARDIN, Laurence. Análise de Conteúdo. Lisboa: Edições 70, 2010.

BORGES, Sandra Marques. Fatores determinantes da evasão escolar no ensino superior: o estudo de caso DOILES/ ULBRA de Itumbiara. $77 \mathrm{f}$. Dissertação (Mestrado Profissional em Desenvolvimento Regional) - Faculdades Alves Faria. 2011.

BRASIL. Lei no 9394, de 20 de dezembro de 1996. Estabelece as Diretrizes e Bases Nacionais. Diário Oficial da União. Brasília: Gráfica do Senado, ano CXXXIV, n. 248, 23/12/96, 27833-27841.

BRASIL. Lei no 11.096, de 13 de janeiro de 2005. Institui o Programa Universidade para Todos - PROUNI, 2005. Presidência da República. Brasília, DF: Diário Oficial da União. Disponível em: <http://www.planalto.gov.br/ccivil_03/_Ato2004-2006/2005/LEI/ L11096.htm>. Acesso em: 20 jun 2013. 
BRASIL. Projeto de Lei no 8035/2010 Aprova o Plano Nacional de Educação para o decênio 2011-2020. 2011. Disponível em: <http:// www.planalto.gov.br/ccivil_03/Projetos/PL/2010/msg701-101215.htm>. Acesso em: 20 jun de 2013.

DETREGIACHI FILHO, Edson. A evasão escolar na educação tecnológica: estudo de uma unidade do centro estadual de educação tecnológica Paula Souza. 127 f. Tese (Doutorado em Educação) - Universidade Estadual Paulista. 2012.

INEP. Censo da Educação Superior: 2010 - resumo técnico. - Brasília: Instituto Nacional de Estudos e Pesquisas Educacionais Anísio Teixeira, 2013. Disponível em: <http://download.inep.gov.br/educacao_superior/censo_superior/resumo_tecnico/resumo_tecnico_ censo_educacao_superior_2010.pdf>.Acesso em: 10 jun 2013.

INEP. Censo da Educação Superior: 2011 - resumo técnico. - Brasília: Instituto Nacional de Estudos e Pesquisas Educacionais Anísio Teixeira, 2013. Disponível em: <http://download.inep.gov.br/educacao_superior/censo_superior/resumo_tecnico/resumo_tecnico_ censo_educacao_superior_2011.pdf>.Acesso em: 10 jun 2013.

LOPES, Ruth Gonçalves de Faria; LISNIOWSKI, Simone Aparecida; JESUS, Girlene Ribeiro de. Políticas Públicas de Educação Superior a distância: um estudo preliminar das causas de evasão em curso de pedagogia a distância oferecido no âmbito do sistema Universidade Aberta do Brasil. In: Reunião

Anual da ANPEd, 35. Porto de Galinhas: ANPED. 2012.

LOURENÇO, Grasiele Aparecida. Estratégias de Relacionamento para Retenção de Clientes: um estudo de caso em uma instituição de ensino superior privada na Região Metropolitana de Campinas. Dissertação (Mestrado Profissional em Administração) - Universidade Metodista de Piracicaba. São Paulo. 2011.

MELLO, Elena Maria Billig; COSTA, Fátima Terezinha Lopes da; MOREIRA, Jacira Cardoso de (Org.). Pedagogia Universitária: campo de conhecimento em construção. Cruz Alta: Unicruz, 2005.

PEREIRA FILHO, Edgar. Compromisso com o graduar-se, com a instituição e com o curso: estrutura fatorial e relação com a evasão. 89 f. Dissertação (Mestrado em Educação) - Universidade Estadual de Campinas, São Paulo. 2012.

PIACENTINI, Claudia Cristina. Reprovação, Abandono e Evasão: Um estudo de caso no Curso de Bacharelado em Zootecnia da Universidade Tecnológica Federal do Paraná. Dissertação (Mestrado em Educação) - Universidade Tecnológica Federal do Paraná. Paraná. 2012.

PINTO, Marialva Linda Moog. Qualidade da Educação Superior e o PROUNI: Limites e possibilidades de uma política de inclusão. Tese (Doutorado em Educação) - Universidade do Rio dos Sinos. São Leopoldo. 2010.

RISTOFF, Dilvo. Universidade em foco: reflexões sobre a Educação Superior. Florianópolis: Insular, 1999.

ROCHA, Terezinha Cristina da Costa. Políticas Públicas para o Ensino Superior: estudo sobre a inclusão e o desempenho acadêmico dos bolsistas do PROUNI em uma IES privada de Minas Gerais. Dissertação (Mestrado em Educação) - Pontifícia Universidade Católica de Minas Gerais, Minas Gerais. 2012.

SILVA, João Augusto Ramos e. A Permanência de Alunos nos Cursos Presenciais e a Distância de Administração: contribuições para gestão acadêmica. 275f. Tese (Doutorado em Administração) - Fundação Getúlio Vergas, Rio de Janeiro. 2012. 
VELLOSO, Jacques; CARDOSO, Claudete Batista. Evasão na Educação Superior:alunos cotistas e não cotistas na Universidade de Brasília. In: Reunião Anual da ANPEd, 31. Caxambu: ANPED. 2008.

\section{Endereço para correspondência:}

Pricila Kohls dos Santos

Calle de Los Arcos, 5 - Escalera derecha, Planta 8, Puerta 4

CP 28033

Madrid, Espanha

Recebido em: jun./2014

Aceito em: ago./2014 